\title{
THE HIGH ELEVATION OF C-REACTIVE PROTEIN LEVELS AT ADMISSION REPRESENTS AN EARLY MORTALITY PREDICTOR IN PATIENTS WITH COMPLICATED INTRA-ABDOMINAL INFECTIONS
}

\author{
E. Dimitrov*, G. Minkov, E. Enchev, S. Nikolov, A. Petrov, Y. Yovtchev \\ Department of Surgical Diseases, University Hospital "Prof. Dr. Stoyan Kirkovich", \\ Stara Zagora, Bulgaria
}

\begin{abstract}
PURPOSE: The aim of this study was to evaluate the highly elevated CRP levels at admission as a mortality predictor in patients with complicated intra-abdominal infections (cIAIs).

METHODS: This retrospective study involved 78 adult patients with diagnosis cIAIs admitted to the Department of Surgical Diseases at a University Hospital Stara Zagora from January 2017 to October 2018. CRP concentrations, white blood cells (WBC) count, qSOFA score and SIRS criteria were determined at admission. We compared their prognostic performance using the area under receiver operating characteristics (AUROC) curves and analyzed the coordinates of the curves.

RESULTS: Of the 78 enrolled patients twenty (25.6\%) died during hospitalization. ROC Curve analysis revealed CRP as the best mortality predictor (AUROC $=0.787$ ). The pairwise comparison of ROC curves showed prognostic superiority of CRP compared to WBC (AUROC $=0.787$ vs. $0.511, \mathrm{p}=$ 0.0194 ) and SIRS (AUROC $=0.787$ vs. 0.579, $\mathrm{p}=0.0315$ ) in outcome prediction. The identified sensitivity and specificity for CRP cut-off value $=210 \mathrm{mg} / \mathrm{L}$ were $75.0 \%$ and $81.0 \%$, respectively.

CONCLUSION: We found highly elevated CRP levels at admission as a significant prognostic biomarker in patients with cIAIs.
\end{abstract}

Key words: C-reactive protein, biomarkers, complicated intra-abdominal infections, sepsis, prognosis, outcome, mortality

\section{INTRODUCTION}

At the end of the second decade of the $21^{\text {st }}$ century, complicated intra-abdominal infections (cIAIs) remain a serious challenge for general surgeons and critical care medicine physicians, because of their unacceptably high mortality rates. Nowadays cIAIs comprise nearly twenty percent of sepsis in Intensive Care Units (ICUs) and moreover, they hold second place after pneumonia as a cause for infectious morbidity and mortality (1).

In cIAIs, the infectious process spreads beyond the affected intra-abdominal organ and results either in acute local or diffuse peritonitis (2). Usually, cIAIs lead to sepsis that can evolve

Correspondence to: Evgeni N. Dimitrov, $M D$ Department of Surgical Diseases, University Hospital "Prof. Dr. Stoyan Kirkovich” Stara Zagora, 2 Gen. Stoletov Str. Bulgaria; e-mail: evgeni_d1984@yahoo.com tel: +359887609943 into a septic shock, a multiple organ failure and eventually to death, if any delay in treatment occurs. Therefore, early prognosis and timely management are extremely important for the favorable outcome.

Over the years a lot of different biomarkers for early prognostic evaluation were investigated and yet none has shown the required characteristics. The first acute-phase reactant to be characterized as sensitive marker of tissue damage, inflammation and infection was C-reactive protein (CRP) (3). Currently CRP is one of most widely used biomarkers in clinical practice. A lot of researchers explore CRP as a diagnostic biomarker and reported a good accuracy for detection abdominal infection or postoperative complications (4-9). However, the prognostic role of CRP in patients with cIAIs remains unclear. The authors that investigate the predictive performance of CRP 
in cIAIs are not many (10-13) and only few of them have looked at CRP levels at admission as a mortality predictor. (14-16). Despite the routine clinical use of CRP, no study (to the best of our knowledge) analyzed its high elevation at admission as a marker for the detection of fatal outcomes in patients with cIAIs.

Therefore, our aim was to evaluate the highly elevated CRP levels at admission, before an administration of any kind of treatment, as a predictor of death in patients with complicated intra-abdominal infections.

\section{MATERIAL AND METHODS}

This was a single center retrospective study conducted in the Department of Surgical Diseases at a University Hospital "Prof. Dr. Stoyan Kirkovich" Stara Zagora. We retrieved data for 78 adult patients admitted to the Department of Surgical Diseases (DSD) from the Emergency Department (ED) and operated on for cIAIs between January 2017 and October 2018. For this time period in DSD were admitted eighty-eight patients with cIAIs. Missing data about CRP levels were found in seven patients, two patients died preoperatively and one was under 18 years old. Finally, seventy-eight patients were included in the retrospective analysis.

Demographic information, laboratory results, clinical parameters and outcomes were collected from the patients' medical records through a systematic survey. CRP levels and white blood cells (WBC) count were determined from the data at admission to DSD. The qSOFA score was calculated according to values of systolic blood pressure (SBP) $\leq 100$ $\mathrm{mmHg}$, respiratory rate (RR) $\geq 22 /$ minute and a Glasgow Coma Scale (GCS) $<15$ points (1 point for each criterion to yield a score value between 0 and 3). A positive score was identified as $\geq 2$ points (17). A presence of systemic inflammatory response syndrome (SIRS) was defined as two or more of the following 4 signs: a heart rate $>90 / \mathrm{min}$, tachypnea $>20 / \mathrm{min}$, a temperature $<36^{\circ} \mathrm{C}$ or $>38^{\circ} \mathrm{C}$ and a WBC count $<4 \times 10^{9} / \mathrm{L}$ or $>12 \times 10^{9} / \mathrm{L}$ (18). SIRS and qSOFA were calculated based on patients' clinical data at admission.

Statistical analyses were performed using SPSS Statistics 19.0 (IBM, Chicago, Illinois, USA) and MedCalc 14.8.1 (MedCalc
Software, Ostend, Belgium). The sensitivity, specificity and area under receiver operating characteristics (AUROC) curves were computed to evaluate the ability of each inflammatory marker and score to predict the fatal outcome. The comparison of ROC curves was performed using De Long's method. Continuous variables were presented as mean $( \pm \mathrm{SD})$ for normally distributed data or median (IQR) for non-normally distributed data. Comparisons of group differences for continuous variables were performed by Student $\mathrm{t}$ Test or Mann-Whitney $\mathrm{U}$ test. Categorical variables were expressed as frequency (\%) and compared by Chi-square test or Fisher exact test. Statistically, significant $\mathrm{p}$-value was considered lower than 0.05 .

\section{RESULTS \\ General characteristics}

Of the seventy-eight patients, twenty-five $(25.6 \%)$ had a poor outcome. The patients who died had higher average age than those who survived $(73.25 \pm 12.18$ vs. $54.21 \pm 18.29, \mathrm{p}<$ $0.0001)$. Mortality was significantly higher in patients with chronic renal failure $(\mathrm{p}=0.004)$ and oncological disease $(p=0.017)$. No significant differences between survivors and non-survivors were found according to gender $(\mathrm{p}=0.593)$, exudate $(\mathrm{p}=0.071)$, source $(\mathrm{p}=$ $0.058)$ and spread of peritonitis $(p=0.065)$, presence of arterial hypertension $(p=0.219)$ and diabetes $(\mathrm{p}=0.687)$ (Table 1).

\section{Clinical parameters and scores}

CRP levels were significantly elevated in patients who died $(240.75 \pm 99.21 \mathrm{mg} / \mathrm{L}$ vs. $127.59 \pm 100.73 \mathrm{mg} / \mathrm{L}, \mathrm{p}<0.0001)$. There was no significance in outcome prediction according to leucocytosis ( $\mathrm{p}=0.886$ ). Eight patients $(10.3 \%)$ had GCS $<15$ at admission, none of them survived ( $\mathrm{p}<$ 0.0001). Significant differences between survivors and non-survivors were determined according to SBP $\leq 100 \mathrm{mmHg}$ $(\mathrm{p}=0.017)$ and $\mathrm{RR} \geq 22 /$ minute $(\mathrm{p}=$ 0.002 ). We observed a qSOFA score $\geq 2$ points in eight patients $(10.3 \%)$, only one $(1.7 \%)$ of them survived $(\mathrm{p}<0.0001)$. No significance was found for a body temperature $>38^{\circ} \mathrm{C}(\mathrm{p}=1.000)$, a heart rate $>90 /$ minute $(\mathrm{p}=0.110)$ and a SIRS $(\mathrm{p}=$ 0.300) (Table 2). 
Table 1. General characteristics

\begin{tabular}{|l|l|l|l|l|}
\hline Variable & Total population & Survivors(n=58) & Non-Survivors(n=20) & p value \\
\hline $\begin{array}{l}\text { Sex, } \mathbf{n}(\%) \\
\text { male/female }\end{array}$ & $43(55.1) / 35(44.9)$ & $33(76.7) / 25(71.4)$ & $10(23.3) / 10(28.6)$ & 0.593 \\
\hline Age, years \pm SD & $59.09 \pm 18.82$ & $54.21 \pm 18.29$ & $73.25 \pm 12.18$ & $<0.0001$ \\
\hline $\begin{array}{l}\text { Source, } \mathbf{n}(\%) \\
\text { Appendix }\end{array}$ & $19(24.4)$ & $18(31.0)$ & $1(5.0)$ & 0.058 \\
$\begin{array}{l}\text { Stomach/Duodenum } \\
\text { Hepatobiliary system }\end{array}$ & $17(21.8)$ & $12(20.7)$ & $5(25.0)$ & \\
Colon/Rectum & $14(17.9)$ & $12(20.7)$ & $4(20.0)$ & \\
Small intestine & $2(2.6)$ & $7(12.1)$ & $7(35.0)$ & \\
Female reproductive & $4(5.1)$ & $1(1.7)$ & $1(5.0)$ & \\
system & & $4(6.9)$ & $0(0)$ & \\
Other & $6(7.7)$ & $4(6.9)$ & $2(10.0)$ & \\
\hline $\begin{array}{l}\text { Peritonitis, n(\%) } \\
\text { Local } \\
\text { Diffuse }\end{array}$ & $29(37.2)$ & $25(43.1)$ & $4(20.0)$ & 0.065 \\
\hline $\begin{array}{l}\text { Exudate, } \mathbf{n}(\%) \\
\text { Serous }\end{array}$ & $49(62.8)$ & $33(56.9)$ & $16(80.0)$ & \\
$\begin{array}{l}\text { Purulent } \\
\text { Feculent }\end{array}$ & $12(15.4)$ & $10(17.2)$ & $2(10.0)$ & 0.071 \\
\hline $\begin{array}{l}\text { Comorbidity, } \mathbf{n}(\%) \\
\text { Malignancy }\end{array}$ & $62(79.5)$ & $47(81.0)$ & $15(75.0)$ & \\
$\begin{array}{l}\text { Hypertension } \\
\text { Diabetes }\end{array}$ & $4(5.1)$ & $1(1.7)$ & $3(15.0)$ & \\
Chronic Renal Failure & $15(19.2)$ & $7(12.1)$ & $8(40.0)$ & \\
\hline
\end{tabular}

Table 2. Clinical parameters and scores

\begin{tabular}{|c|c|c|c|c|}
\hline Variable & Total population & Survivors(n=58) & Non-Survivors(n=20) & p value \\
\hline SBP $\leq 100 \mathrm{mmHg}, \mathrm{n}(\%)$ & $15(19.2)$ & $7(12.1)$ & $8(40.0)$ & 0.017 \\
\hline$R R \geq 22 / \min , n(\%)$ & $10(12.8)$ & $3(5.2)$ & $7(35.0)$ & 0.002 \\
\hline GCS $<15, \mathrm{n}(\%)$ & $8(10.3)$ & $0(0)$ & $8(40.0)$ & $<0.0001$ \\
\hline Heart rate $>90 / \min , \mathbf{n}(\%)$ & $24(30.8)$ & $15(25.9)$ & $9(45.0)$ & 0.110 \\
\hline $\mathrm{t}>38^{\circ} \mathrm{C}, \mathrm{n}(\%)$ & $13(16.7)$ & $10(17.2)$ & $3(15.0)$ & 1.000 \\
\hline WBC, $10^{9} / \mathrm{L}$ (IQR) & $12.0(9.2-16.0)$ & $12.0(9.6-15.4)$ & $11.3(7.4-16.8)$ & 0.886 \\
\hline $\mathrm{CRP}, \mathrm{mg} / \mathrm{L} \pm \mathrm{SD}$ & $156.60 \pm 111.41$ & $127.59 \pm 100.73$ & $240.75 \pm 99.21$ & $<0.0001$ \\
\hline SIRS, n(\%) & $24(30.8)$ & $16(27.6)$ & $8(40.0)$ & 0.300 \\
\hline qSOFA $\geq 2, n(\%)$ & $8(10.3)$ & $1(1.7)$ & $7(35.0)$ & $<0.0001$ \\
\hline
\end{tabular}

\section{Sensitivity, Specificity and AUROCs}

CRP showed the best prognostic the performance $($ AUROC $=0.787,95 \% \mathrm{CI}=$ $0.680-0.872$ ). A cut-off value $=210 \mathrm{mg} / \mathrm{L}$ permitted prediction of mortality with a sensitivity of $75 \%$ and specificity of $81 \%$. The qSOFA score was observed with a little worse predictive performance than CRP $($ AUROC $=$ $0.746,95 \%$
$\mathrm{CI}=0.635-0.838)$. The computed sensitivity and specificity for qSOFA score $\geq 2$ points were $35.0 \%$ and $98.3 \%$, respectively. In contrast, WBC count $($ AUROC $=0.511,95 \%$ $\mathrm{CI}=0.395-0.626)$, and SIRS (AUROC = $0.579,95 \% \mathrm{CI}=0.462-0.690)$ showed poor prognostic value (Figure 1), (Table 3).

Table 3. Sensitivity, Specificity and AUROCs

\begin{tabular}{|l|l|l|l|l|}
\hline Variable & Cut-off value & Sensitivity,\% & Specificity,\% & AUROC \\
\hline CRP & $210 \mathrm{mg} / \mathrm{L}$ & 75.0 & 81.0 & $0.787(0.680-0.872)$ \\
\hline WBC & $12.01 \times 10^{9} / \mathrm{L}$ & 55.0 & 50.0 & $0.511(0.395-0.626)$ \\
\hline qSOFA & $\geq 2$ points & 35.0 & 98.3 & $0.746(0.635-0.838)$ \\
\hline SIRS & $\geq 2$ points & 40.0 & 72.4 & $0.579(0.462-0.690)$ \\
\hline
\end{tabular}




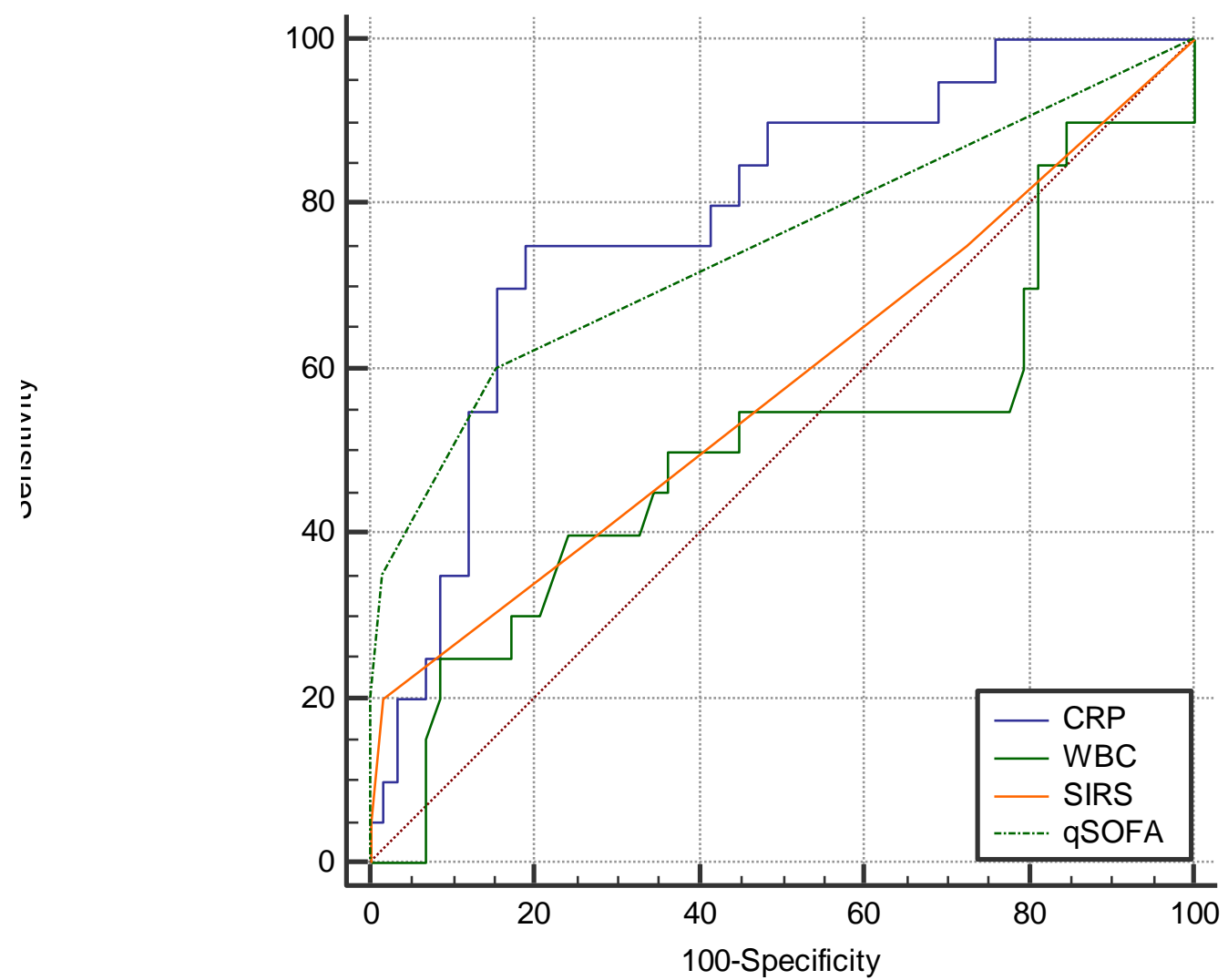

Figure 1. Comparison of ROC Curves

Using a pairwise comparison of ROC Curves we observed prognostic superiority of CRP than WBC (difference between areas $=0.276$, $95 \% \mathrm{CI}=0.0446-0.508, \mathrm{p}=0.0194)$ and SIRS (difference between areas $=0.208,95 \% \mathrm{CI}=$ $0.0184-0.398, \mathrm{p}=0.0315)$, and comparability to qSOFA (difference between areas $=0.0409$, $95 \% \mathrm{CI}=-0.121-0.203, \mathrm{p}=0.6195)$ (Table 4).

Table 4. Pairwise comparison of ROC curves

\begin{tabular}{|l|l|l|l|}
\hline & CRP WBC & CRP SIRS & CRP qSOFA \\
\hline Difference between areas & 0.276 & 0.208 & 0.0409 \\
\hline Standart Error & & & \\
\hline 95\% CI & 0.118 & 0.0968 & 0.0825 \\
\hline Significance & $0.0446-0.508$ & $0.0184-0.398$ & $-0.121-0.203$ \\
\hline
\end{tabular}

\section{DISCUSSION}

Complicated intra-abdominal infections involve a wide spectrum of patient populations, which makes the suggestion of a general treatment strategy a difficult task and demonstrates the necessity of an individual approach to each patient (19). Early prognostic assessment of cIAIs provides an opportunity to differentiate the patients at a higher risk of death and a chance to change the inadequate management plan in an early stage, so the adverse outcome to be improved. These findings show the need for specific methods, which would help for the early prognosis and could determine the aggressiveness of conservative and surgical treatment.

Prediction of mortality using routinely and available biomarkers represents a quick and cheap way to provide adequate information about the risk of a fatal outcome in every hospital all around the world. Nowadays CRP is one of the most commonly used markers in everyday practice. CRP is for sure not ideal biomarker, but it could be very helpful in terms of identifying patients at a higher risk of 
adverse outcome, who need ICU admission, close monitoring and re-evaluation of the aggressiveness of management. The validity of CRP in estimating the prediction of mortality in patients with cIAIs is still not well known. In this regard there are contradictory data in the literature.

We found only one study (14) that considered the high elevation of CRP concentrations at admission as a mortality predictor in patients with cIAIs. Unfortunately, the authors did not analyze these findings. Significant differences between survivors and non-survivors were observed according to CRP levels $>200 \mathrm{mg} / \mathrm{L}$ ( $\mathrm{p}<0.0001)$. This cut-off value could predict the fatal outcome with a sensitivity of $25 \%$ and specificity of $86.7 \%$.

In our study the highly elevated CRP levels at admission showed significant association with the fatal outcome. We have identified a much higher sensitivity of $75 \%$ and similar specificity of $81 \%$ for CRP threshold $=210$ $\mathrm{mg} / \mathrm{L}$.

Pandey et al. (16) investigated preoperative CRP levels in 86 surgical patients with an acute abdomen. At a cut-off value $>150 \mathrm{mg} / \mathrm{L}$ the observed sensitivity and specificity were $90 \%$ and $42.1 \%$, respectively. The mortality rate was higher among patients with preoperative CRP levels $>150 \mathrm{mg} / \mathrm{L}$ as compared to those patients with preoperative CRP levels $\leq 150 \mathrm{mg} / \mathrm{L}(\mathrm{p}=0.049)$.

Mulari et Leppäniemi (15) observed that the highest CRP examined during the first three days after the operation differs significantly according to outcome $(192,0-361 \mathrm{mg} / \mathrm{L}$ vs. $216,27-378 \mathrm{mg} / \mathrm{L}, \mathrm{p}=0.015)$, however, its levels at admission did not reach statistical significance between patients who died and those who survived.

In our study, CRP concentrations at admission were significantly elevated in non-survivors compared to survivors $(240.75 \pm 99.21 \mathrm{mg} / \mathrm{L}$ vs. $127.59 \pm 100.73 \mathrm{mg} / \mathrm{L}, \mathrm{p}<0.0001)$.

No prognostic significance for CRP levels examined preoperatively was found by several authors - Yamamoto et al. (13) in patients with colorectal perforation (survivors $124 \pm 110$ $\mathrm{mg} / \mathrm{L}$ vs. non-survivors $68 \pm 68 \mathrm{mg} / \mathrm{L}, \mathrm{p}=$ 0.171), Akcay et al. (11) in patients with perforation of peptic ulcer (survivors $150 \pm 79$ $\mathrm{mg} / \mathrm{L}$ vs. non-survivors $234 \pm 143 \mathrm{mg} / \mathrm{L}, \mathrm{p}$
$>0.05$ ), small bowel (survivors $175 \pm 105 \mathrm{mg} / \mathrm{L}$ vs. non-survivors $130 \pm 54 \mathrm{mg} / \mathrm{L}, \mathrm{p}>0.05)$ and colon (survivors $199 \pm 176 \mathrm{mg} / \mathrm{L}$ vs. nonsurvivors $288 \pm 315 \mathrm{mg} / \mathrm{L}, \mathrm{p}>0.05)$, and Pehlivanli et al. (20) in patients with secondary peritonitis (survivors $190.85 \mathrm{mg} / \mathrm{L}$ vs. nonsurvivors $187.78, \mathrm{p}=0.79$ ).

Two studies examined CRP levels postoperatively in surgical patients with cIAIs as a predictor of mortality. Neither Suarez dela-Rica et al. (12) (survivors $192 \mathrm{mg} / \mathrm{L}$ vs nonsurvivors $268 \mathrm{mg} / \mathrm{L}, \mathrm{p}=0.07)$, nor Pupelis et al. (10) (survivors $150 \mathrm{mg} / \mathrm{L}$ vs. non-survivors $226 \mathrm{mg} / \mathrm{L}, \mathrm{p}=0.058$ ) found significant prognostic value of CRP measured after surgery.

In patients with sepsis CRP also shows conflicting results. Stalder et al. (21) reported very poor prognostic performance $($ AUROC $=$ 0.556), whereat survivors had higher CRP levels at admission than non-survivors (262 $\mathrm{mg} / \mathrm{L}$ vs. $225 \mathrm{mg} / \mathrm{L}, \mathrm{p}=0.383)$. Unlike them, Koozi et al. (22) observed higher CRP levels in non-survivors $(141 \mathrm{mg} / \mathrm{L}$ vs. $95 \mathrm{mg} / \mathrm{L}, \mathrm{p}=$ 0.023 ) as well as Ryoo et al. (23) in septic shock patients (non-survivors $147 \mathrm{mg} / \mathrm{L}$ vs. survivors $119 \mathrm{mg} / \mathrm{L}, \mathrm{p}=0.003$ ).

Our study is the first one (to the best of our knowledge) that analyzes ROC Curves of CRP, WBC, SIRS and qSOFA using a pairwise comparison analysis. Thus, we found the superiority of CRP than WBC and SIRS and comparability to qSOFA score in outcome prediction.

As limitations of our study, we can highlight the single-center experience, the retrospective design, and the small sample size.

\section{CONCLUSION}

In patients with complicated intra-abdominal infections, the high elevation of C-reactive protein levels examined on admission represents an early and important predictor of death. At admission, non-survivors have significantly higher CRP levels than survivors, whereat a threshold $=210 \mathrm{mg} / \mathrm{L}$ is associated with an increased risk of an unfavorable outcome.

\section{REFERENCES}

1. Vincent $\mathrm{Jl}$, Rello $\mathrm{J}$, Marshall $\mathrm{J}$, et al. International study of the prevalence and outcomes of infection in intensive care units. Jama 2009; 302(21):2323-9; 
2. Menichetti F, Sganga G. Definition and classification of intra-abdominal infections. J Chemother. 2009 Jul;21 Suppl 1:3-4;

3. Pepys MB, Baltz ML. Acute phase proteins with special reference to $\mathrm{C}$-reactive protein and related proteins (pentaxins) and serum amyloid A protein. Adv Immunol. 1983;34:141-212;

4. Ohzato H, Yoshizaki K, Nishimoto $\mathrm{N}$, Ogata A, Tagoh $\mathrm{H}$, Monden $\mathrm{M}$, et al. Interleukin-6 as a new indicator of inflammatory status: detection of serum levels of interleukin-6 and C-reactive protein after surgery. Surgery. 1992;111:201-9.;

5. Mustard Jr RA, Bohnen JM, Haseeb S, Kasina R. C-reactive protein levels predict postoperative septic complications. Arch Surg. 1987;122:69-73.;

6. Póvoa P, Coelho L, Almeida E, Fernandes A, Mealha R, Moreira P, Sabino H. Creactive protein as a marker of infection in critically ill patients. Clin Microbiol Infect 2005;11:101-8.;

7. Almeida AB, Faria G, Moreira H, Pinto-deSousa J, Correia-da-Silva P, Maia JC. Elevated serum C-reactive protein as a predictive factor for anastomotic leakage in colorectal surgery. Int J Surg. 2012;10:8791.;

8. Orati JA, Almeida P, Santos V et al. Serum C-reactive protein concentrations in early abdominal and pulmonary sepsis. Rev Bras Ter Intensiva. 2013;25(1):6-11.;

9. Silvestre J, Rebanda J, Lourenço C, Póvoa P. Diagnostic accuracy of C-reactive protein and procalcitonin in the early detection of infection after elective colorectal surgery - a pilot study. BMC Infect Dis. 2014;14:444. doi:10.1186/14712334-14-444;

10.Pupelis G, Drozdova N, Mukans M, Malbrain ML. Serum procalcitonin is a sensitive marker for septic shock and mortality in secondary peritonitis. Anaesthesiol Intensive Ther. 2014 SepOct;46(4):262-73. doi: 10.5603/AIT.2014.0043.;

11.Idris Akcay, Alexis K. Okoh, Orcun Yalav et al. The prognostic value of ProCalcitonin, CRP and thyroid hormones in secondary peritonitis; A single-center prospective study. Ulus Travma Acil Cerrahi Derg. 2014; 20(5): 343-352;

12.Alejandro Suarez-de-la-Rica, Emilio Maseda, Víctor Anillo et al. Biomarkers (Procalcitonin, C Reactive Protein, and
Lactate) as Predictors of Mortality in Surgical Patients with Complicated IntraAbdominal Infection. Surgical Infections Jun 2015.346351.http://doi.org/10.1089/sur.2014.178;

13. Yamamoto $\mathrm{T}$, Kita $\mathrm{R}$, Masui $\mathrm{H}$, et al. Prediction of mortality in patients with colorectal perforation based on routinely available parameters: a retrospective study. World J Emerg Surg. 2015;10:24. doi:10.1186/s13017-015-0020-y.;

14.Sartelli, M., Abu-Zidan, F.M., Labricciosa, F.M. et al. Physiological parameters for Prognosis in Abdominal Sepsis (PIPAS) Study: a WSES observational study. World $J$ Emerg Surg 14, 34 (2019). https://doi.org/10.1186/s13017-019-0253-2;

15.K. Mulari, A. Leppäniemi SEVERE SECONDARY PERITONITIS FOLLOWING GASTROINTESTINAL TRACT PERFORATION. Scandinavian Journal of Surgery 93: 204-208, 2004;

16.Pandey VK, Singh R, Nagarwal N et al. Effect of CRP and lactate clearance in predicting outcome of emergency abdominal surgeries. Int Surg $J$ 2018;5:2978-83.;

17.Singer M, Deutschman CS, Seymour CW, Shankar-Hari $M$ et al. The Third International Consensus Definitions for Sepsis and Septic Shock (Sepsis-3). JAMA. 2016 Feb 23;315(8):801-10. doi: 10.1001/jama.2016.0287.;

18. Bone RC, Balk RA, Cerra FB, et al. Definitions for sepsis and organ failure and guidelines for the use of innovative therapies in sepsis. Chest 1992;101:164455.;

19. Sartelli M, Abu-Zidan FM, Catena F, et al. Global validation of the WSES Sepsis Severity Score for patients with complicated intra-abdominal infections: a prospective multicentre study (WISS Study). World J Emerg Surg. 2015;10:61. doi:10.1186/s13017-015-0055-0;

20.Pehlivanli F, Agalar F, Agalar C et al. The value of CRP, IL-6, leptin, cortisol, and peritoneal caspase-3 monitoring in the operative strategy of secondary peritonitis. Ulus Travma Acil Cerrahi Derg. 2011;17(5):390-395;

21. Stalder G, Que YA, Calzavarini S, et al. Study of Early Elevated Gas6 Plasma Level as a Predictor of Mortality in a Prospective Cohort of Patients with Sepsis. PLoS One. 2016;11(10):e0163542. Published 2016 Oct 27. doi:10.1371/journal.pone.0163542; 


\section{DIMITROV E., et al.}

22.Koozi H, Lengquist M, Frigyesi A. Creactive protein as a prognostic factor in intensive care admissions for sepsis: A Swedish multicenter study. J Crit Care. 2020; 56:73-79. doi:10.1016/j.jcrc.2019.12.009;
23.Ryoo, S.M., Han, K.S., Ahn, S. et al. The usefulness of C-reactive protein and procalcitonin to predict prognosis in septic shock patients: A multicenter prospective registry-based observational study. Sci Rep 9, $6579 \quad$ (2019). https://doi.org/10.1038/s41598-019-429727 